\title{
STEEL-CONCRETE VIADUCTS IN THE ORASTIE-SIBIU HIGHWAY: A EUROCODE COMPLIANT PROJECT
}

Aldo Giordano, PH.D. Professor of Structural Engineering, ITALROM Inginerie Internationala, e-mail: a.giordano@italrominginerie.com

Ionuţ Radu Răcănel, Associate Professor, Technical University of Civil Engineering Bucharest, e-mail: ionut@cfdp.utcb.ro

Giovanni Voiro, Structural Engineer, ITALROM Inginerie Internationala, e-mail: g.voiro@italrominginerie.com

\section{Abstract}

This paper is intended to show the design of two composite bridges along the OrastieSibiu motorway, from the basic concepts, applied without the need for a clause-by- clause checking of codes and standards, to the construction methods.

The bridges are seismically isolated in the longitudinal direction, while transversally the seismic action is distributed among the piers.

Calculations have been carried out through state of the art procedures, taking into account form effect of the cross section. For this reason, different FE models have been set up to study different aspects of the behavior, with increasing degrees of approximation. For example, "beam" elements have been utilised to investigate global effects both in the linear and non linear range, while more accuate 2D and 3D elements have been used for refined cases such as stress checks and local buckling analyses.

The present paper goes into detail in particular for what concerns some of the most interesting parts of the design process for the specific case. Namely, time dependent properties of the materials have been considered, and extensive "staged construction" analyses have been carried out to ensure safety in each phase of the complex life of the bridges, while at the same time guaranteeing significant cost savings.

Keywords: steel-concrete composite deck, FE analysis, seismic isolation, time-dependent material properties, staged construction

\section{INTRODUCTION}

The two viaducts share the same cross section and statical scheme, while differing for what concerns the total length. In particular, the first one covers a total of $680 \mathrm{~m}$ with $60 \mathrm{~m}$ main spans and $40 \mathrm{~m}$ lateral spans, while the second is $250 \mathrm{~m}$ long with 60 and $35 \mathrm{~m}$ spans. Both are of the "continuous girder" type and feature no joints throughout the whole length. Together with the cassions, 
ROMANIAN JOURNAL

OF TRANSPORT INFRASTRUCTURE

the transverse beams carry the concrete slab, cast upon longitudinal predalles The following figure depicts the overall plan for both bridges

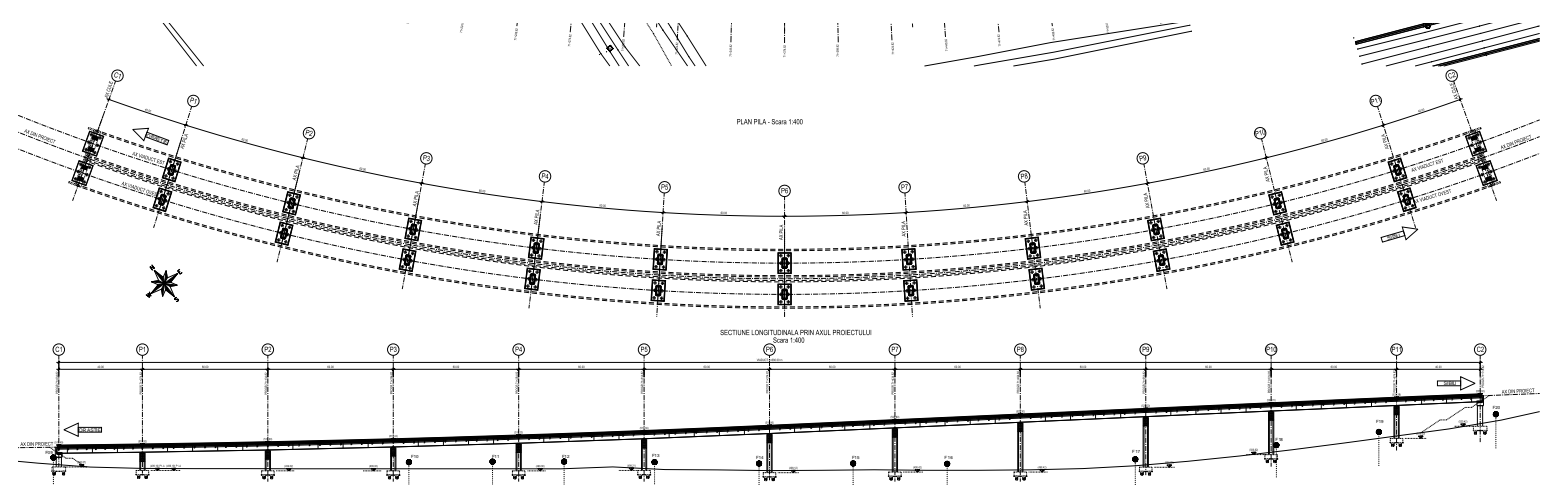

Figure 1. Plan scheme of the longer bridge

The original tender documents featured a totally different scheme, with shorter spans and a fully concrete construction. Once the Contractor had been awarded the commission, it turned out evident that a more cost effective solution could be adopted by changing the typology into what we eventually came up with, here represented in the following figure 2.

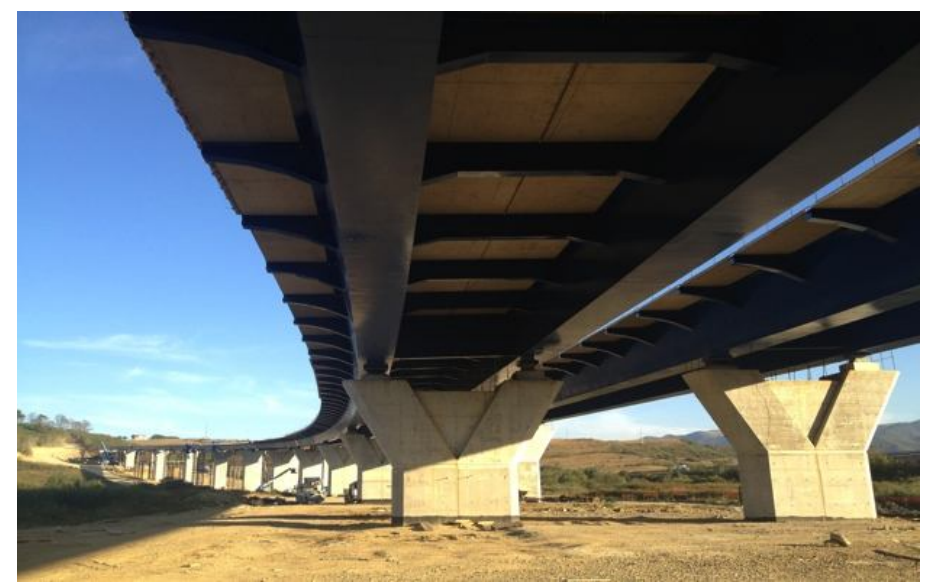

Figure 2. Bridge view from the bottom

Since the overall cost was the key parameter, refined analyses have been carried out throughout the design process, using different software codes as a function of the specific aspect to be investigated, here in the following described. Along with the necessary national annexes, the whole projects has been carried out with reference to the Eurocodes. 


\section{THE DESIGN PROCEDURE}

Since the structure is characterized by a certain complexity and different levels of structural behavior, it was necessary to set up various analysis models to meet all the design requirements.

In particular, reference was made to 3 computation models:

1. Partial model made up of 3 spans: aimed at evaluating local stresses in the various loading conditions and at different construction and life stages for strength, stability and deformability checks.

2. Local model of the rc slab: aimed at the determination of the amount of reinforcement required.

3. Global model: it is a less detailed model for studying the overall the dynamic behavior of the structure and then calculating the seismic actions to be used in the design of the support devices, piers and abutments.

4. Additional ultra-refined model to study post-elastic behaviour

In the following, for brevity reasons, model n.2, which is the less interesting from a scientific point of view, is not described.

\subsection{Refined partial model}

The model was realized with the FEM software MIDAS/GEN 2010 using plate elements (mixed behavior) and beam elements.

The model is limited to only 3 spans, and this simplification is made possible by the recurrent scheme along the longitudinal development of the bridge. It is a rather detailed model through which it is possible to capture the behavior by identifying areas subject to higher stress concentrations, thus allowing to easily check the capacity of the structure towards the design actions.

As customary in the the modeling of medium to large structures, construction phases that clearly influence the final result of the analysis have been taken into account. Namely:

1. The girder is put in place creating a succession of simply supported beams.

2. the main girders are rendered continuous at supports (deformations due to self-weight are not retrieved)

3. Casting of the concrete deck in central areas of the spans. the load of the complements and workers is carried by the steel structure alone acting as a continuous beam. Casting at midspan first and, as well as being statically convenient, allows to avoid early cracking phenomena. 
ROMANIAN JOURNAL

OF TRANSPORT INFRASTRUCTURE

4. The slab in the middle of the spans cures and the section becomes composite

5. Casting of the concrete slab at supports

6. The slab at the supports cures and the section becomes composite along the whole length

7. Taking into account the reologic phenomena, checks in the ultimate conditions are performed considering the code loads.


Figure 3. FEM model - 3D views

Considering the concrete curing for $100000 \mathrm{gg}$ is not a question of a real construction phase, but it is equally important as the time variable that governs shrinkage and creep affects the behavior in the way a general migration of the stresses from the concrete slab to the steel girder takes place. The used model for evaluating time effect is of course the CEB-FIP one, represente by the following picture:

Of course, thermal effect have been taken into account both for what concerns daily and seasonal variations. 
ROMANIAN JOURNAL

OF TRANSPORT INFRASTRUCTURE

Aldo Giordano, Ionuţ Radu Răcănel, Giovanni Voiro,

Steel - concrete viaducts in the Orastie-Sibiu highway: A Eurocode compliant project

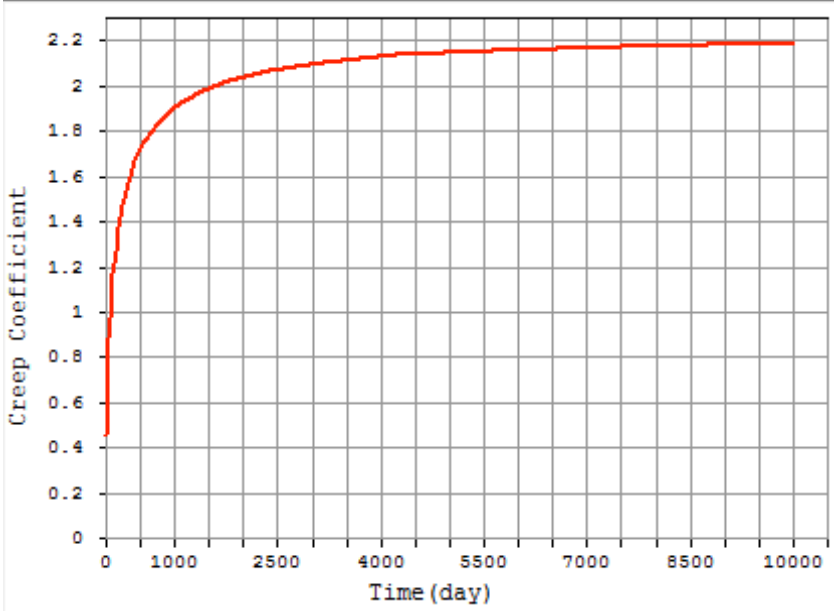

Figure 4. CEB-FIP creep model

The structural models in the different phases are shown in the following pictures.

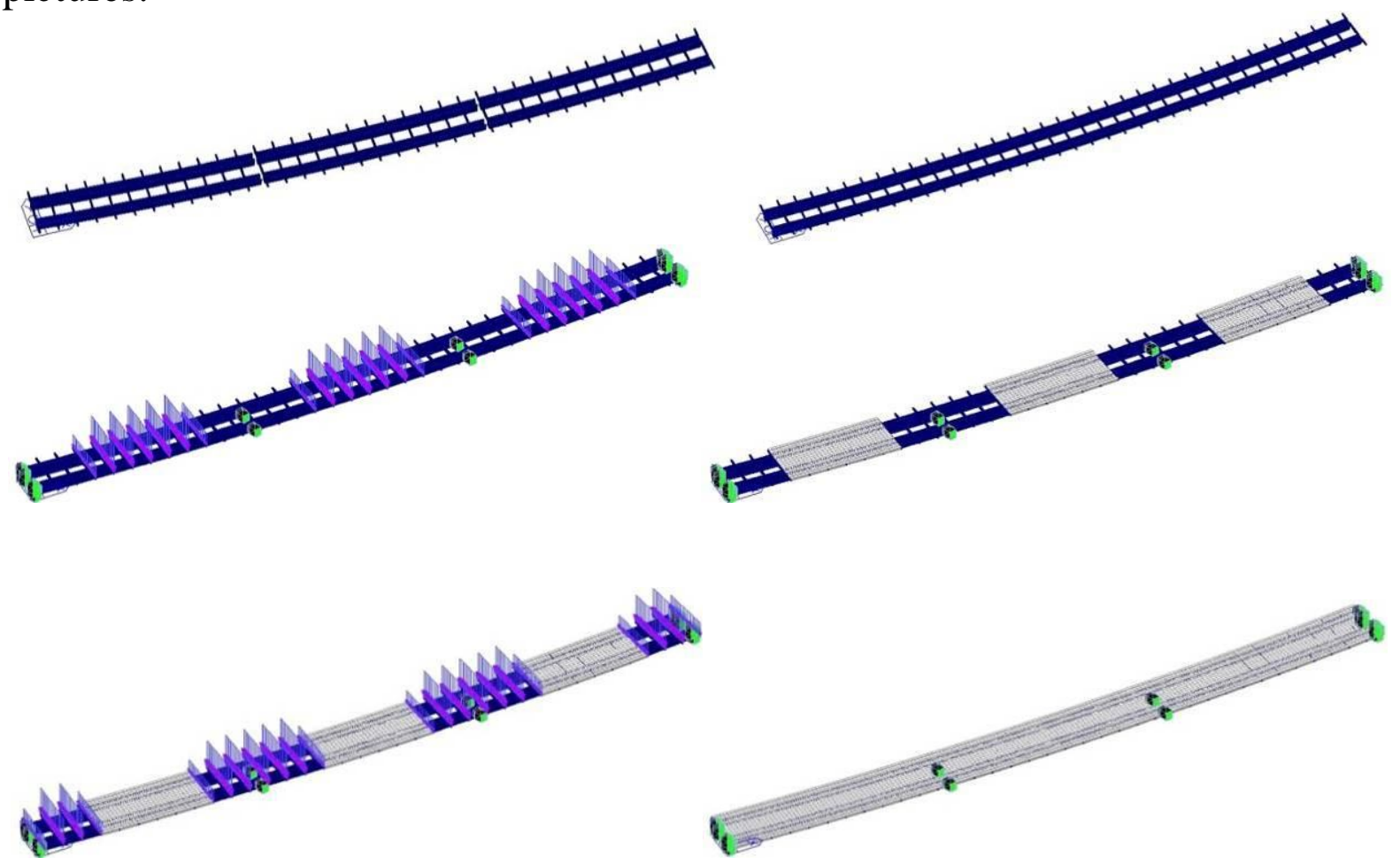

Figure 5. Subsequent phases for staged analysis

The results deriving from such model have been used for the required code checks in all respects. 
ROMANIAN JOURNAL

OF TRANSPORT INFRASTRUCTURE

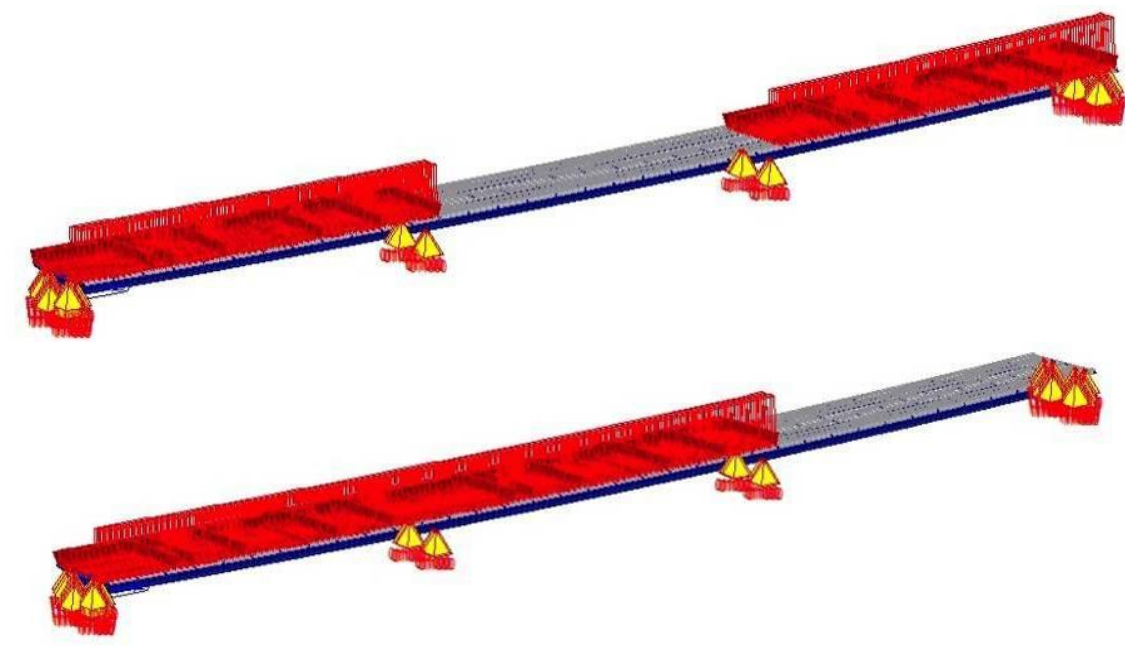

Figure 6. Different loads condition for maximizing actions in different parts of the structure

\subsection{Global seismic analyses}

The two bridges are seismically isolated in the longitudinal direction, while in the transversal one seismic forces are distributed among the piers. The isolation devices are friction pendulums. The following figures shows one of the isolation devices actually used in the project.
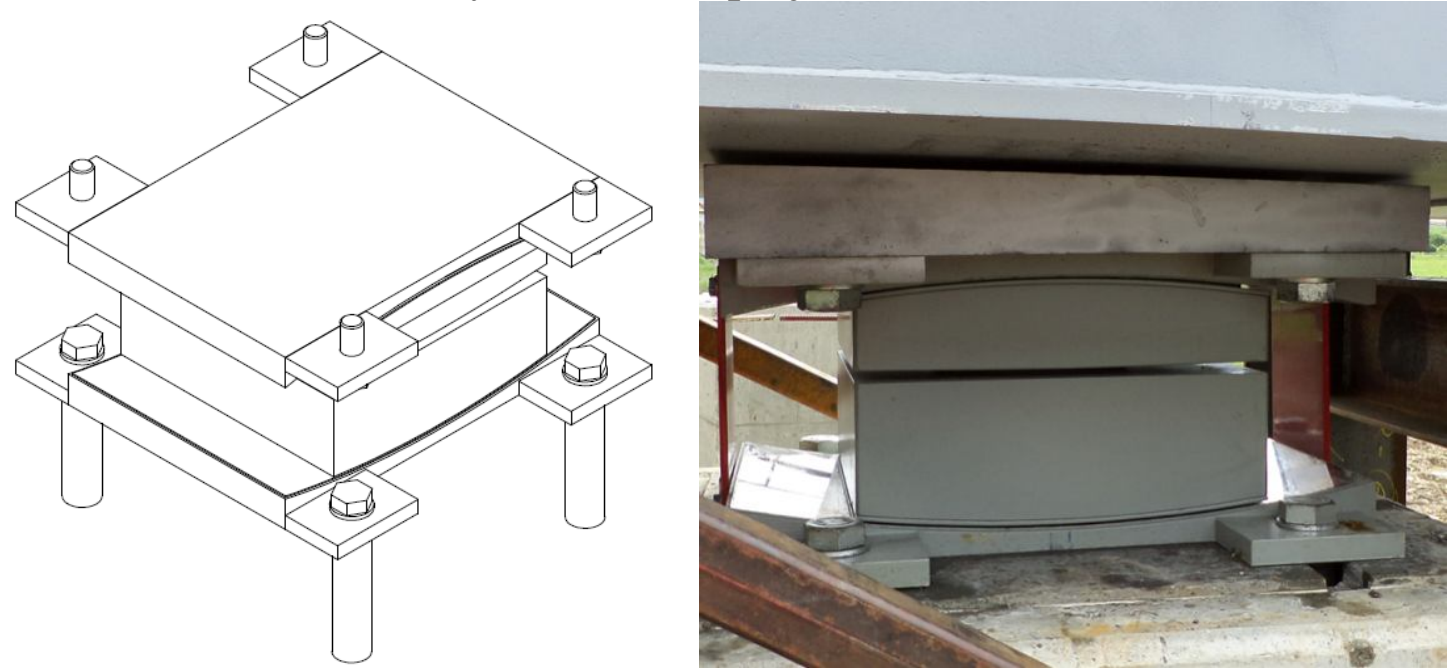

Figure 7. Seismic isolation devices

From a computational point of view, the isolators have been introduced in the analysis model as elastic links, with suitable characteristics in terms of stiffness (different in each direction) and damping. 
ROMANIAN JOURNAL

OF TRANSPORT INFRASTRUCTURE

Aldo Giordano, Ionuţ Radu Răcănel, Giovanni Voiro,

Steel - concrete viaducts in the Orastie-Sibiu highway: A Eurocode compliant project

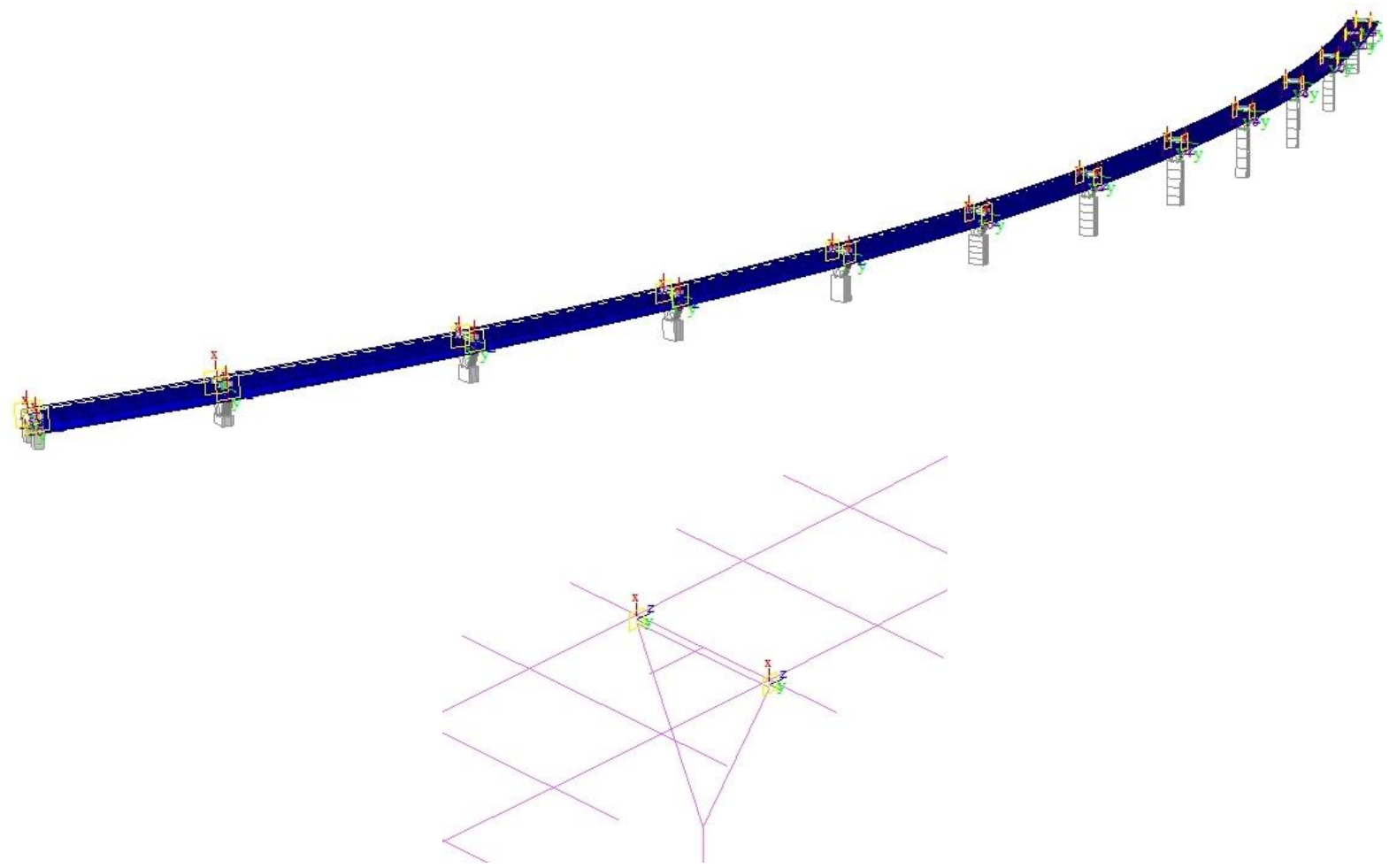

Figure 8. Global model with link elements

This model has been subjected to seismic excitation using the Eurocode spectra (with national parameters) in terms of pseudo-accelerations and displacements, these latter being of particular importance with regard to the specific scheme.

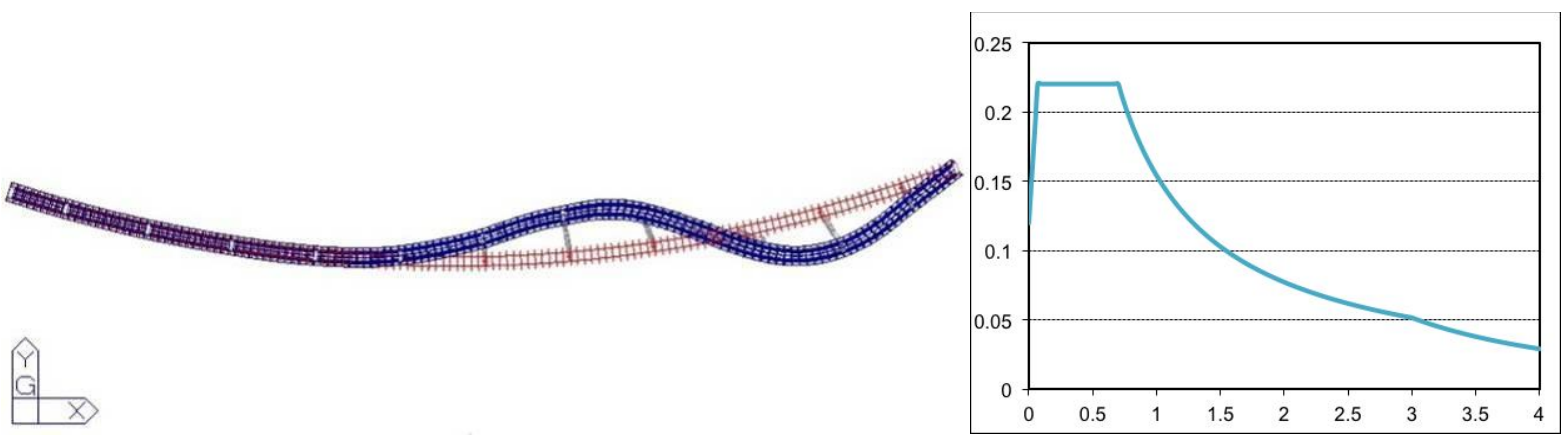

Figure 9. One of the vibration modes and earthquake spectrum 
ROMANIAN JOURNAL

OF TRANSPORT INFRASTRUCTURE

\section{ASSESSMENT OF CAISSON BEHAVIOUR}

Due to discrepancies of the constructed structural elements and the execution drawings, in particular for what concerns the cut holes in the transversal stiffeners, the validator Prof. Ing. Ionuț Radu Răcănel and the designer Prof. Ing. Aldo Giordano agreed to perform advanced FE analyses aimed at studying the behaviour of the structure in the non-linear range. The well-known commercial software Abaqus ${ }^{\circledR}$ has been chosen, in order to obtain the best possible reliability of the results. The model reproduces $12 \mathrm{~m}$ long portion of the right hand caisson, corresponding to a real construction section, down to the smallest possible detail. The model has been realised using the original shop drawings by the steel manufacturer.
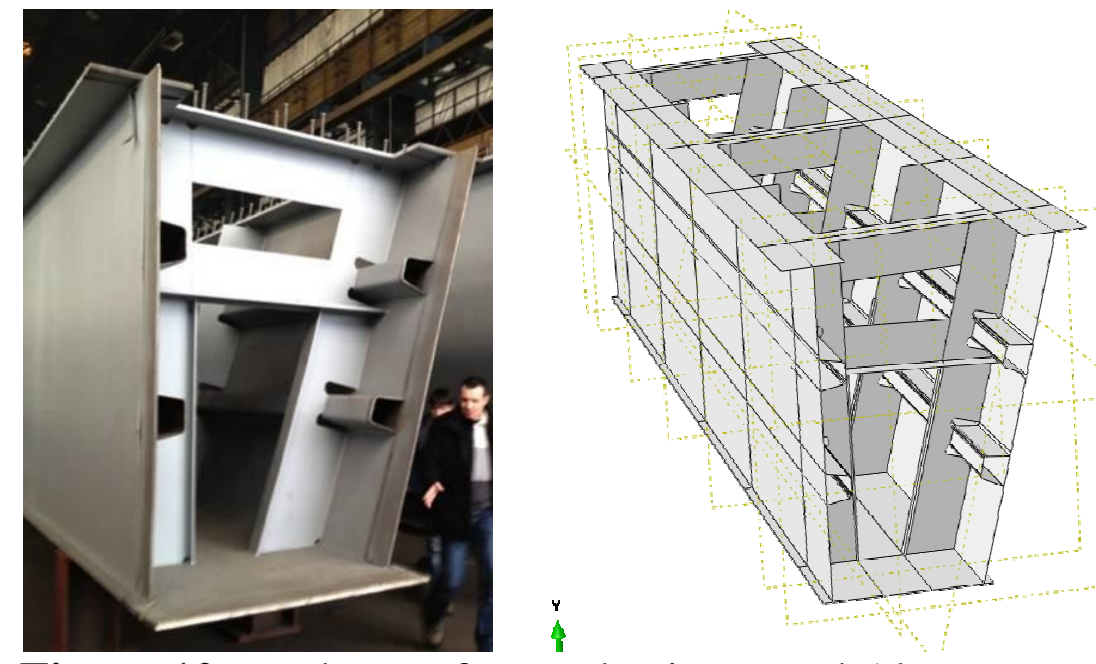

Figure 10. Real manufactured caisson and Abaqus model

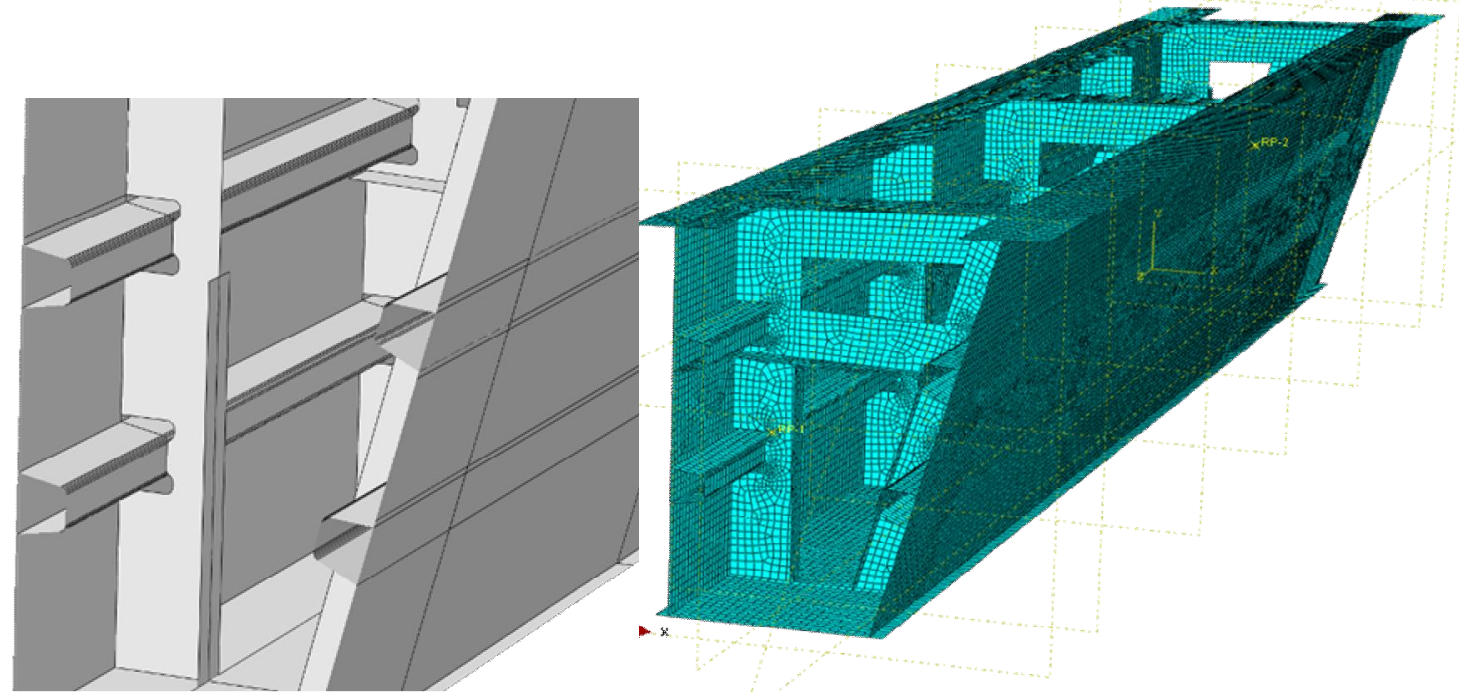

Figure 11 Detail at stiffeners and FE mesh 
ROMANIAN JOURNAL

OF TRANSPORT INFRASTRUCTURE

The geometry has been discretised using a quad-dominated mesh, resulting in a model made up of 66,714 8-node reduced integration (S8R) elements, and only 377 triangular elements. No element is distorted, with average minimum angle of $47^{\circ}$ and worst of $27^{\circ}$. Such aspect is deemed to be particularly important, since it is recognised that poor mesh can trigger wrong results, expecially when bucking or non-linear behaviour is involved.

Standard plasticity model has been used. Moderate kinematic hardening is also included in case cyclic analyses should be performed. The mechanical characteristics are give in true stress - true strain, using Ramber-Osgood formulation
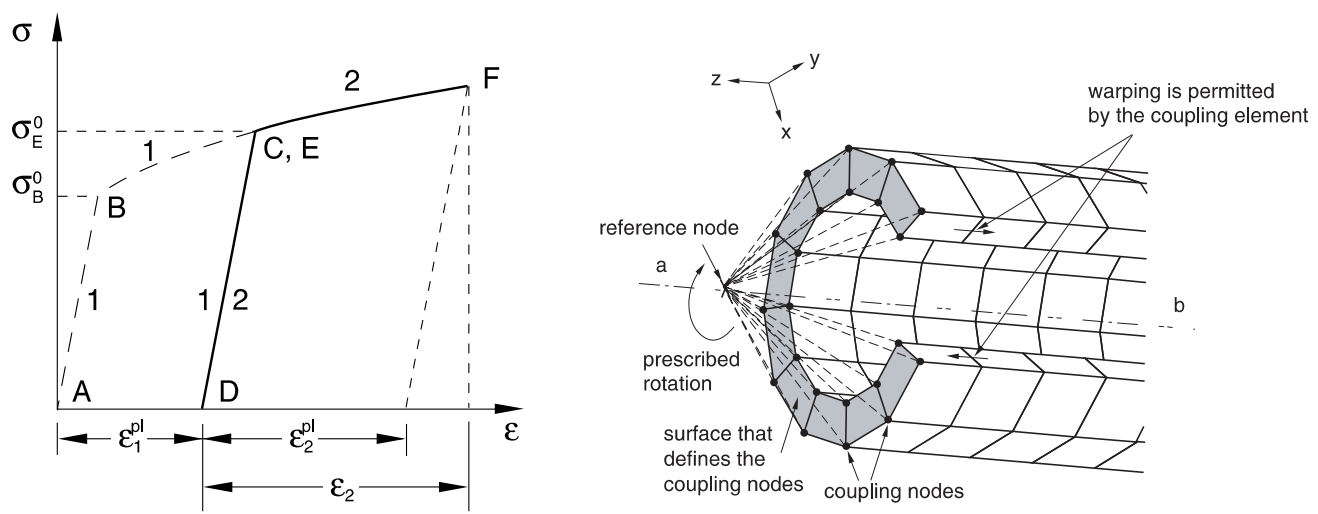

Fig. 12. Material behavior and boundary condition scheme

- The Young's modulus is assumed equal to: $205 \mathrm{GPa}$

- First yield occurs at $355 \mathrm{MPa}$

In all analyses, the geometrical non linearity is taken into account and the solver is set up to take into account both large displacements and large deformations.

5\% initial residual stresses are considered in the initial step of the analyses

An MPC (Multi Point Constraint) type "beam" has been used to constrain the ends of the model. This type of kinematic link ties rigidly al the degrees of freedom of a set of nodes to the motion of a reference node. In this manner, it is easy to apply the desired displacement field to the model boundary.

Note that this type of constraint transforms the degrees of freedom in the deformed configuration, and thus permits geometrical nonlinearity. Also warping is permitted.

Different conditions, both in terms of displacement and rotations, have been applied to the model in order to account for the possibility of considering different possible positions along the bridge. At any location, cord rotation has 
been considered in order to neglect rigid motion. It has been found that the most severe condition is obtained when one end is fixed and a displacement is applied at the other end. Since the problem might be severely non linear and buckling may occur at any execution time, the modified Riks algorithm has been used in all analyses. It is a well known arc-length based procedure, capable of following the response path even in strongly unstable branches. When the displacement field deriving form the general bridge analyses are applied, the structure itself remains well within the linear range and values of the equivalent Mises stresses are relatively low. No beginning of instability is detected anywhere, though additional "imperfection" is fictitiously applied by providing $0.5 \%$ horizontal misalignment.
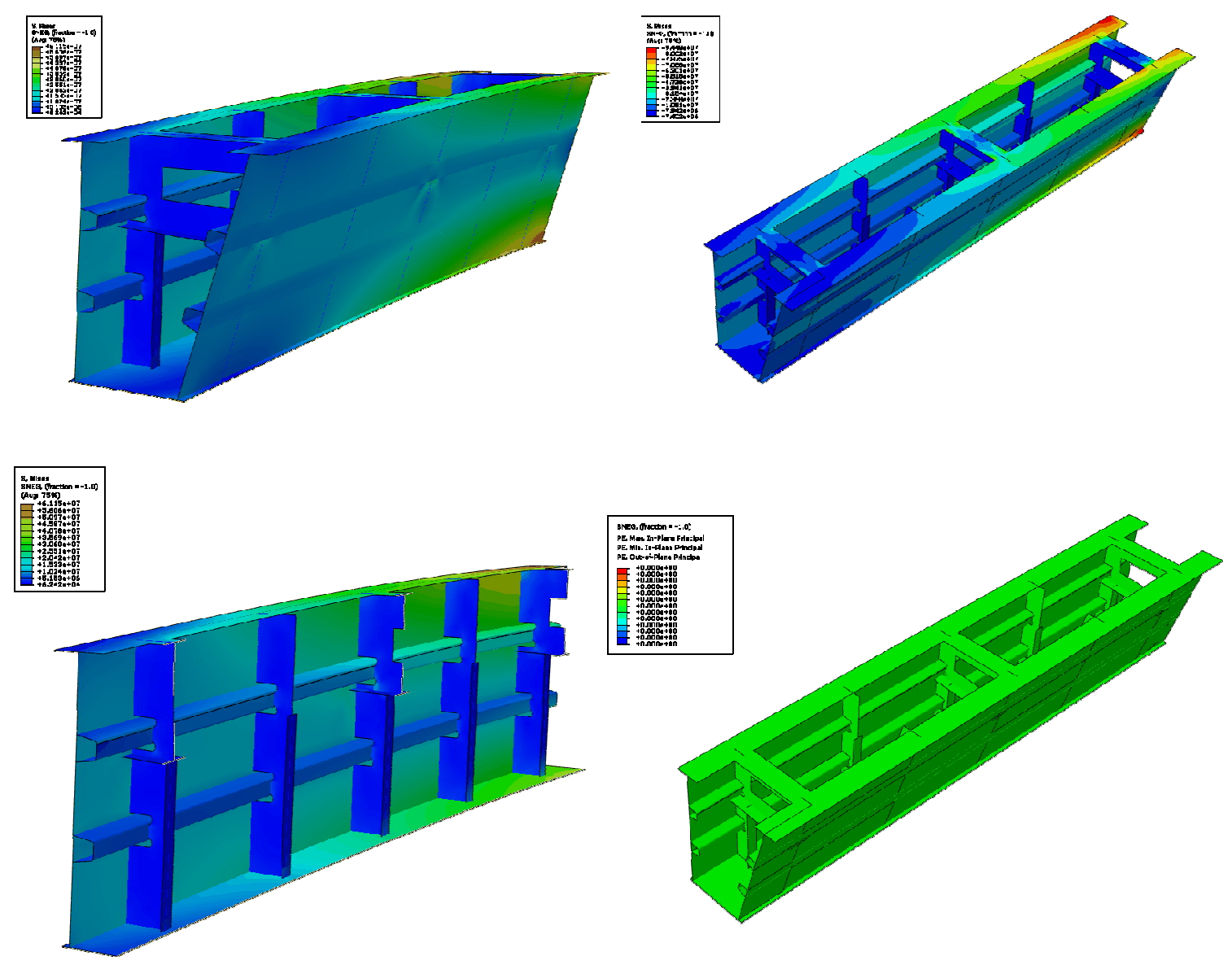

Fig. 13. Equivalent stresses and plastic tensor

In order to detect possible plasticity, the tensor representation of the plastic strain component is very useful. The picture shows zero value throughout the model. For the reasons above, we decided to investigate the behaviour well beyond the realistic deformation that the bridge will ever experience. In 
ROMANIAN JOURNAL

OF TRANSPORT INFRASTRUCTURE

particular a displacement of $0.3 \mathrm{~m}$ is applied. Since the model is $12 \mathrm{~m}$ long, such displacement is incredibly huge with respect to the expected real displacements, so that if any instability is to occur, it is certainly detected. The following picture represents the force-displacement relationship at the reference point. The structure shows a perfectly linear behaviour up to $0.08 \mathrm{~m}$ displacement, with peak strength at $0.1 \mathrm{~m}$. After that, yielding occurs at encastre sections and, after initial softening, the structure follows an indefinitely stable path.
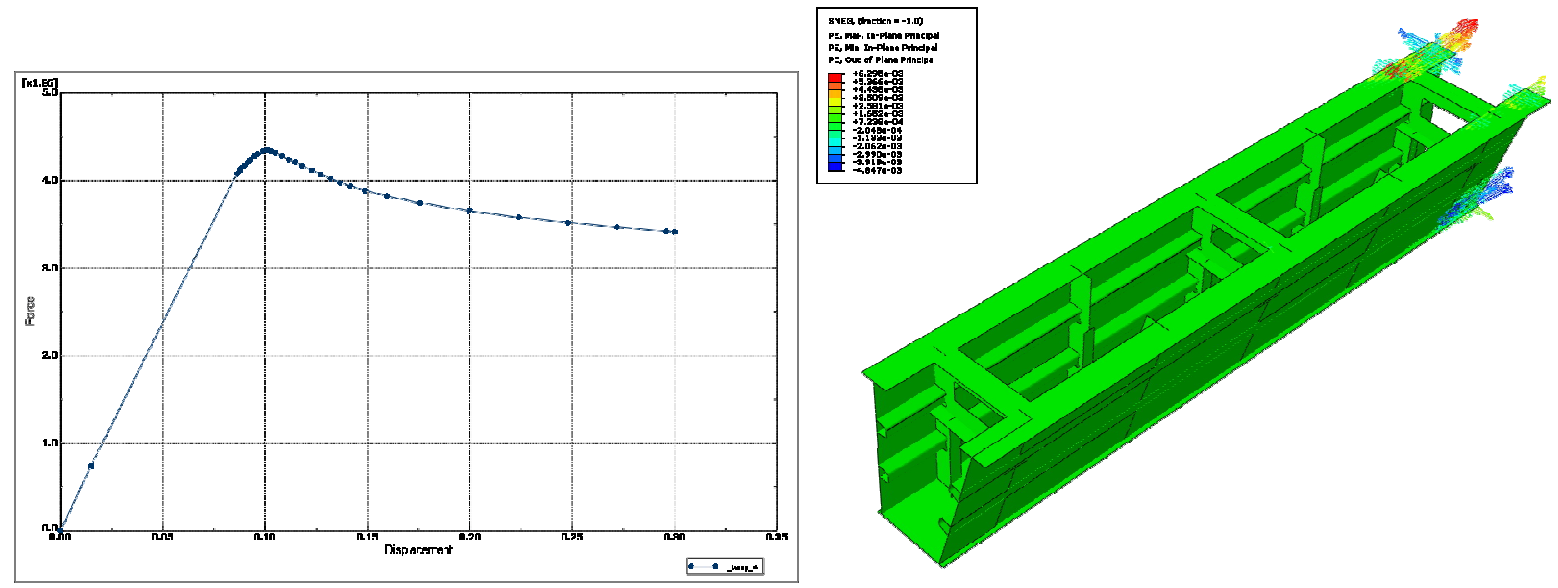

Figure 14 - Force displacement relationship and Plastic strain components:

Within the ranges of expected deformations, the bridge behaves perfectly elastic, with equivalent stresses that are reasonably low, also considering fatigue effects. No instability occurs up to unrealistically high displacements, that have been applied only to investigate the non-linear "reserve" that the scheme can provide.

In particular for what concerns stiffeners, it is shown that they are not severely engaged, and this is probably due to the overall configuration that makes all the elements collaborate appropriately.

\section{ERECTION}

Once all the design issues had been dealt with, a very detailed method statement for construction has been established in order to respect the analysis assumption in each phase of the erection.

The following figures shown some of the construction phases. 


\section{ROMANIAN JOURNAL \\ OF TRANSPORT INFRASTRUCTURE}

Aldo Giordano, Ionuţ Radu Răcănel, Giovanni Voiro,

Steel - concrete viaducts in the Orastie-Sibiu highway: A Eurocode compliant project

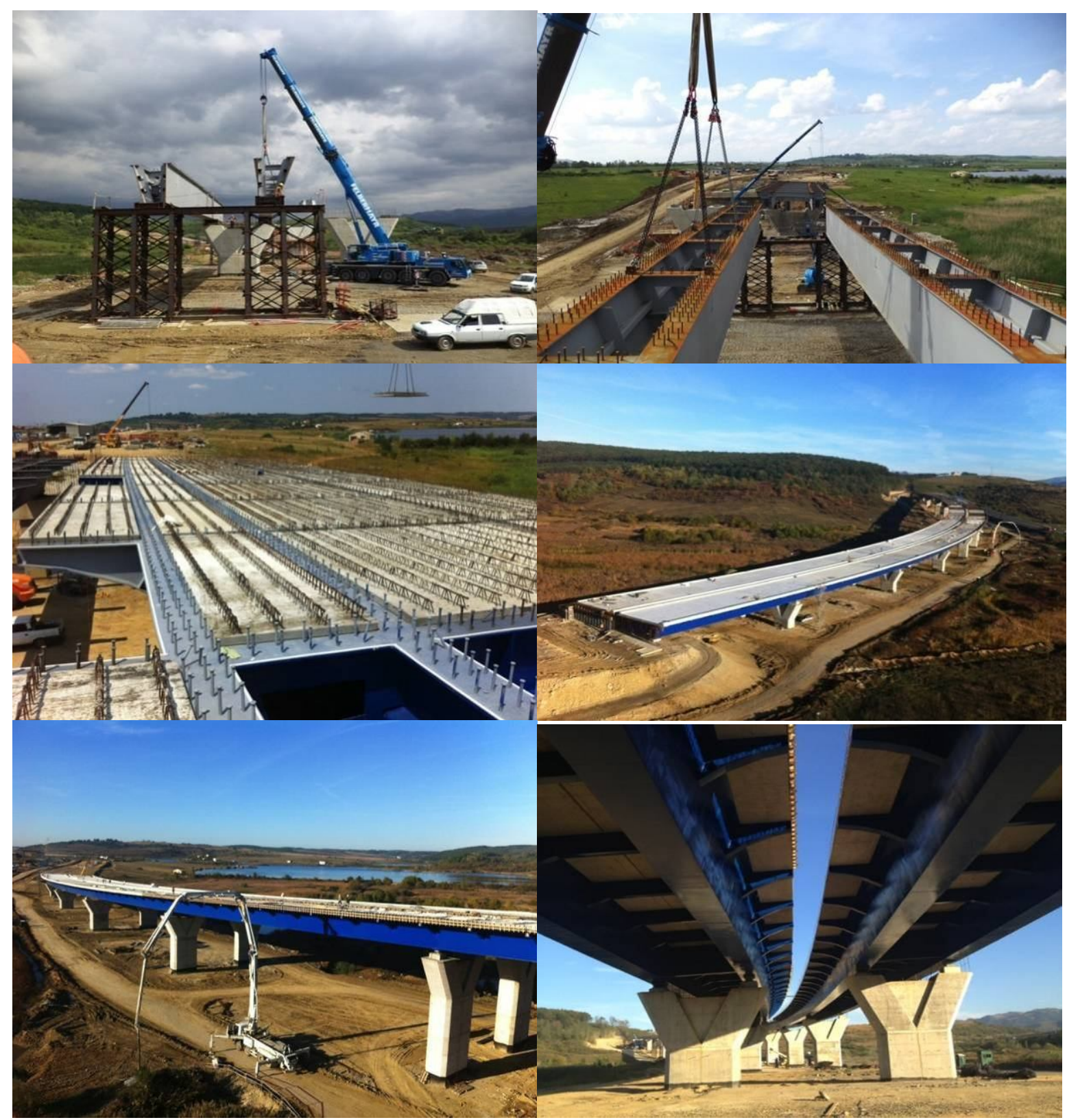

\section{CONCLUSIONS}

This paper, within the limits of these few pages, describes the process the authors have followed in the design of a composite steel-concrete viaduct with some peculiar characteristics. The approach followed has made possible a particularly cost effective realization, while at the same time retaining very good structural performances and beautiful aesthetics. Some concepts, such as shape effects and extensive use of non-linear analysis, have helped in streamlining the process balancing the allegedly opposite needs of cost saving and structural performance. 